\title{
PENGARUH PENAMBAHAN FLUOR PADA RESIN AKRILIK TERHADAP KEKERASAN BASIS GIGI TIRUAN SEBAGIAN
}

\author{
Titik Ismiyati \& Suparyono Saleh \\ Bagian Prostodonsia, Fakultas Kedokteran Gigi, Universitas Gadjah Mada
}

ABSTRAK

Latar Belakang. Penelitian ini adalah salah satu efek pemakaian gigi tiruan sebagian adalah mudah terjadinya karies pada gigi yang masih tinggal. Hal ini karena kecenderungan terbentuknya plak pada permukaan gigi dan abrasi karena klamer pada gigi penyangga. Usaha untuk mencegah karies gigi adalah melakukan tindakan fluoridasi. Macam fluor yang sering digunakan adalah sodium fluorida 2,27\% $\left(\mathrm{NaF}_{2}\right)$. Bahan yang sering digunakan untuk membuat plat dasar gigi tiruan sebagian adalah resin akrilik yang komponennya mengandung polimetil metakrilat.

Tujuan. Penulisan ini untuk mengetahui fluoridasi melalui gigi tiruan yaitu dengan meneliti penambahan fluor pada resin akrilik terhadap sifat kekerasan basis gigi tiruan sebagian.

Metoda. Subyek penelitian berupa 40 plat resin akrilik kuring panas dan kuring dingin yang dicampur dengan sodium fluorida $\left(\mathrm{NaF}_{2}\right)$, ukuran $20 \times 15 \times 2,5 \mathrm{~mm}$. Pencampuran sodium fluorida dan resin akrilik dengan perbandingan $1: 3$. Pada kelom pok 1 resin akrilik kuring panas dicampur dengan sodium fluorida, kelompok II akrilik resin kuring dingin dicampur dengan sodium fluorida, kelompok 3 resin akrilik kuring panas tanpa penambahan sodium fluorida, dan kelompok 4 resin akrilik kuring dingin tanpa penambahan fluor. Uji kekerasan dilakukan dengan menggunakan alat Micro Vickers Hardness Tester. Data yang diperoleh dianalisis dengan menggunakan statistik anava 2 jalur.

Hasil penelitian. Menunjukkan bahwa terdapat perbedaan yang bermakna kekerasan resin akrilik kuring panas dan resin akrilik kuring dingin $(p<0,05)$, dan tidak terdapat perbedaan yang bermakna kekerasan resin akrilik kuring panas dan kuring dingin yang ditambah sodium fluorida dan tanpa penambahan sodium fluorida $(p>0,05)$

Kesimpulan. Penelitian ini adalah penambahan sodium fluorida pada resin akrilik kuring panas dan pada resin akrilik kuring dingin tidak mempengaruhi kekerasan basis gigi tiruan sebagian. Maj Ked Gi, Juni 2011; 18(1): 113-116

Kata kunci: Fluor, Resin akrilik, Kekerasan, Basis gigi tiruan sebagian

\section{ABSTRACT}

Background. One effect of the partial denture wearing is of dental caries easily in remains teeth. It is caused the tendency of the formation of plaque on tooth surface and abrasion due to the claps. Attempts to prevent it fluoridation is applied. Fluor can

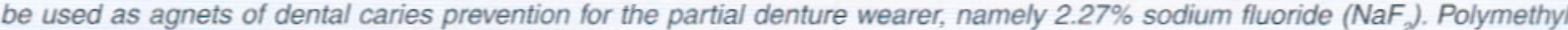
methacrylate is the material which used in making partial denture base. hardness.

The purpose if the study is to determine the effect of fluor addition on acrylic resin removable partial denture base to the

Methods. The research materials are 40 heat cured and cold cured acrylic resin plates in $60 \times 10 \times 2.5 \mathrm{~mm}$ dimension were added with sodium fluoride in 1.3 ratio. Group I : heat cured acrylic resin added with $\mathrm{NaF}_{2}$, group II : cold cured acrylic resin added with $\mathrm{NaF}_{2}$, and group II and group IV : heat cured and cold cured acrylic resin without added with $\mathrm{NaF}_{2}$. All of the subjects were tested by using Vickers Micro Hardness Tester. Data obtained were analyzed using 2 ways of Anova.

The result showed that there were significantly hardness different between heat and cold acrylic resin $(p<0.05)$, there were no significantly hardness different between heat and cold acrylic resin with and without mixed with $\mathrm{NaF}_{2}(p>0.05)$.

The conclusion is there is no hardness effect of the additional $\mathrm{NaF}_{2}$ in heat and cold cured acrylic resin. Maj Ked Gi; Juni 2011; 18(1): 113-116

Key words: Fluor, Resin acrylic, Hardness, Partial denture base

\section{PENDAHULUAN}

Gigi tiruan sebagian lepasan merupakan salah satu pelayanan rehabilitasi gigi pada kehilangan sebagian gigi. Komponen alat tersebut terdiri dari basis dengan atau tanpa perluasan sampai ke sayap bukal atau labial, artifisial gigi dan klamer sebagai retensi. Bahan yang sering digunakan pada pembuatan gig tiruan sebagian lepasan adalah polimetil metakrilat kuring panas dan kuring dingin. Resin akrilik kuring panas sering digunakan sebagai basis gigi tiruan, sedang pada kuring dingin digunaan untuk reparasi, rebasing dan relining gigi tiruan, selain itu juga dapat dipakai sebagai bahan plat alat ortodonsi.

Sebagai alat rehabilitasi, gigi tiruan berfungs untuk estetis, mengembalikan fungsi pengunyahan, bicara, oklusi dan mempertahankan gigi yang masih tinggal. Namun pada pemakaiannya ternyata gigi tiruan sebagian lepasan sering mengakibatkan terjadinya karies gigi, hal ini disebabkan karena kebersihan yang kurang terjaga sehingga terjadi akumulasi plak yang mengubah hubungan bakteri terhadap permukaan gigi, disamping itu adanya perlakuan melepas dan memasang gigi tiruan menimbulkan trauma pada 
gigi sehingga gigi mengalami abrasi atau pengurangan lapisan email yang menjurus kearah terjadinya karies. Gigi tiruan sebagian telah diteliti sebagai penyebab tingginya prevalensi karies dan gingivitis yang dihubungkan dengan kenaikan pembentukan plak pada permukaan gigi. ${ }^{1}$ Pada pemakai gigi tiruan satu rahang maka akan terjadi karies satu gigi atau lebih sebesar $60,5 \%$, sedang pada pemakai gigi tiruan 2 rahang mempunyai satu gigi atau lebih gigi yang karies sebanyak $62,5 \%,{ }^{2}$ oleh karena itu diperlukan cara untuk mencegah terjadinya karies pada pemakai gigi tiruan.

Konsep tentang etilogi karies dapat disebabkan karena adanya faktor- faktor yang saling terkait yaitu host ( gigi ), saliva, mikroorganisme, diet makanan dan waktu. Usaha tindakan untuk pencegahan karies gigi di Kedokteran gigi dipandang masih belum optimal, ${ }^{3}$ walaupun sudah sejak tahun 1890 pendekatan dalam pencegahan karies gigi dengan menggunakan bahan khemoterapi khususnya senyawa fluor telah dilakukan, perlakuan tersebut disebut fluoridasi. Manfaat fluor pada proses pencegahan karies, fluor dapat menambah daya tahan email karena remineralisasi yaitu adanya interaksi antara fluor dengan hidroksi apatit email, maka terjadi pertukaran reaksi antara fluor dengan gugus hidroksi $(\mathrm{OH})$ membentuk fluor apatit yang lebih tahan terhadap asam. Pada gigi yang baru erupsi, permukaan email masih porus, bila gigi tersebut diolesi dengan fluor maka gigi akan mengabsorbsi fluor, sedang pada gigi dewasa, dengan adanya proses abrasi mengakibatkan banyak fluor yang hilang sehingga mudah terjadi karies. ${ }^{4}$

Fluor adalah senyawa halogen, berupa zat yang sangat reaktif dan tidak ditemukan dalam elemen bebas, tetapi ditemukan dalam bentuk senyawa fluor, misalnya calsium flouride, natrium flouride, sodium fluoride atau sebagai sebagian mineral fluorapatit. ${ }^{5}$ Fluor yang terdapat di dalam gigi dalam bentuk fluorapatit, dapat memperkuat email dari kelarutan oleh asam. ${ }^{6}$ Selain itu fluor dapat bertindak sebagai enolase yaitu salah satu enzim yang bekerja pada proses glikolisis. Pada kadar yang tinggi flour mempunyai daya bakterisid bila diberikan dengan konsentrasi tinggi secara lokal dan topikal. ${ }^{7}$ Fluor meningkatkan daya tahan enamel karena adanya remineralisasi, bersifat bakterisid dan menurunkan kemampuan bakteri untuk memproduksi asam.

Sodium fluorida $\left(\mathrm{NaF}_{2}\right)$ adalah salah satu bahan yang digunakan untuk pencegahan karies gigi. Sodium fluorida ditemukan dalam jumlah kecil diudara, air dan tumbuhan atau sebagai partikel proses industri. ${ }^{8}$ Fluorida ini berbentuk serbuk putih, tidak mudah terbakar, sukar larut dalam pelarut organik tetapi larut dalam air. Sodium fluorida mempunyai titik lebur $993^{\circ} \mathrm{C}$, titik didih $1740^{\circ} \mathrm{C}$. Untuk mencegah karies pada gigi penggunaan $\mathrm{NaF}_{2}$ dapat dilakukan dengan berbagai cara yaitu : 1. Tehnik aplikasi langsung atau pengolesan fluor pada email, 2. Kumur dengan larutan yang mengandung fluor, 3. Menyikat gigi dengan pasta gigi yang mengandung fluor, menurut standar Nasional Indonesia kadar fluor yang dipersyaratkan dalam pasta gigi untuk orang dewasa adalah $800-1500 \mathrm{ppm}$, sedangkan bagi pasta gigi anak adalah $500-1000$ ppm, ${ }^{9} 4$. Tehnik penambahan fluor pada plat dasar resin akrilik. Keuntungan penggunaan tehnik ini adalah kuantitas obat ditempatkan tepat sasaran pada tubuh, cepat, dapat mempertahankan stabilitas konsentrasi yang efisien dan aman, dapat digunakan untuk periode yang lama, dan menghasilkan efek terapi konvensional. Sodium fluorida terbukti dapat melepaskan fluor lebih tinggi dibandingkan kalsium fluorida dan ammonium fluorida. ${ }^{1}$

Kemampuan anti kariogenik dari senyawa fluor karena adanya pelepasan unsur fluor. Fluor dapat mengurangi kelarutan email gigi terhadap asam, selain itu fluor bersifat bakteriosid dan menurunkan kemampuan bakteri dalam memproduksi asam. Fluoridasi melalui gigi tiruan dapat dilakukan yaitu dengan merendam gigi tiruan tersebut ke dalam larutan senyawa fluor. ${ }^{10}$ Fluor adalah zat yang mudah larut, termasuk senyawa anorganik, sedangkan pada resin akrilik adalah organik, sehingga apabila dicampurkan akan terjadi ikatan secara mekanik, ${ }^{11}$ Oleh karena itu fluor apabila dicampurkan dengan resin akrilik, maka fluor tersebut dapat terlepas. Fluor harus lepas dari basis gigi tiruan dan kontak dengan gigi asli yang masih tinggal, dengan demikian bakteri dapat terbunuh dan gigi asli terhindar dari karies. ${ }^{4}$

Pelepasan fluor lebih mudah terjadi disebelah sulkus bukal rahang bawah, oleh karena itu penempatan suatu bahan yang dicampur fluor sebaiknya diletakkan disebelah bukal rahang bawah, pada gigi tiruan dibagian sayap bukal merupakan tempat yang strategis. Sayap bukal pada gigi tiruan merupakan perluasan basis gigi tiruan yang berfungsi sebagai retensi dan untuk menutupi tulang alveolar yang terlalu cekung. ${ }^{2}$

Telah berkembang cara fluoridasi dengan menambahkan unsur fluor ke dalam bahan tumpatan gigi misalnya pada bahan tumpatan gigi amalgam, hal ini untuk mencegah terjadinya karies sekunder. ${ }^{8}$ Bahan restorasi amalgam yang mengandung fluor merupakan pengembangan dari bahan amalgam konvensional. Fluoridasi dengan cara menambahkan fluor pada semen glas ionomer dapat dipakai sebagai dasar penambahan fluor dari luar dan ternyata efektif dalam mencegah karies. Penggunaan semen seng fosfat mengandung $\mathrm{SnF}_{2} 10 \%$ yang dipakai untuk penyemenan ring logam pada alat orthodonsi, dapat mencegah penurunan kadar kalsium email gigi secara bermakna. Senyawa $\mathrm{NaF}_{2} 2,27 \%$ adalah larutan yang paling mudah melepaskan fluor dibanding $\mathrm{CaF}_{2} 2,27 \%$ dan $\mathrm{AmF} 0,17 \%$, penelitian ini dilakukan dengan merendam gigi tiruan sebagian dan alat orto 
ke dalam larutan $\mathrm{NaF}, \mathrm{CaF}_{2}$ dan AmF. Sodium fluori$\mathrm{da}(\mathrm{NaF})$ terbukti dapat melepaskan fluor lebih tinggi dibandingkan dengan kalsium fluorida dan amonium fluorida. ${ }^{1,10}$

Pemberian fluor dalam kadar rendah dan dilakukan dalam periode yang lama merupakan cara upaya pencegahan karies yang paling baik. ${ }^{12}$ Fluor dapat mengubah sifat permukaan plat, karena flour dapat mempengaruhi sifat penyerapan air. ${ }^{13}$ Bahan gigi tiruan yang ideal harus tahan terhadap kekuatan mekanis, diantaranya adalah tahan terhadap abrasi pada pemakaian normal, goresan. ${ }^{14}$ Salah satu bentuk uji ketahanan terhadap abrasi adalah uji kekerasan permukaan bahan. Kekerasan bahan resin akrilik idealnya tidak boleh kurang dari $10 \mathrm{~g} / \mathrm{mm}^{2} .{ }^{15}$ Uji kekerasan permukaan biasa dipergunakan untuk mengetahui kemampuan suatu bahan terhadap abrasi. Sifat ini penting karena akan mempengaruhi lama pemakaian gigi tiruan. ${ }^{8}$ Uji kekerasan permukaan adalah kemampuan permukaan bahan terhadap penetrasi indentor. Beberapa alat yang sering dipergunakan untuk uji kekerasan permukaan bahan adalah Vickers, Knoop dan Brinell.

Berdasarkan uraian tersebut maka timbul permasalahan : Apakah penambahan fluor pada gigi tiruan sebagian resin akrilik dapat mempengaruhi sifat kekerasan basis gigi tiruan sebagian tersebut? Tujuan penelitian adalah untuk mengetahui pengaruh penambahan fluor pada resin akrilik terhadap sifat mekanik bahan yaitu kekerasan plat dasaer gigi tiruan sebagian. Hipotesis yang diajukan pada penelitian ini adalah penambahan fluor pada resin akrilik berpengaruh terhadap kekerasan basis gigi tiruan sebagian.

\section{METODA PENELITIAN}

Bahan dan alat penelitian yang dipakai dalam penelitian ini adalah : resin akrilik kuring dingin, resin akrilik kuring panas, sodium fluorida $\left(\mathrm{NaF}_{2}\right) 2,27 \%$, gips, bahan poles, spesimen logam ukuran $20 \times 15 \times$ $2,5 \mathrm{~mm}$, mangkuk karet dan pengaduk, micro Vickers Hardness Tester, mesin poles, alat vakum, alat vibrator

Subyek penelitian dibuat dengan cara menanam specimen logam ukuran $60 \times 15 \times 2,5 \mathrm{~mm}$ dalam kuvet, sehingga didapatkan cetakan model. Jumlah subyek penelitian pada masing -masing kelompok sejumlah 10 buah. Pembuatan subyek kelompok 1 caranya resin akrilik panas (serbuk : cairan $=25$ gr : $10 \mathrm{ml}$ ) dicampur dengan $\mathrm{NaF}_{2} 2 \%(0,056 \mathrm{gr})$ Pencampuran dilakukan dalam pot porselin, setelah adonan mencapai fase dough, adonan dimasukkan ke dalam cetakan model. Dilakukan pengepresan, Dilakukan proses polimerisasi dengan cara penggodogan. Setelah itu dilakukan pemolesan. Pembuatan subyek kelompok 2, caranya sama dengan kelompok 1 tetapi tanpa penggodogan. Resin akrilik kuring di- ngin, serbuk : cairan $=30 \mathrm{gr}: 10 \mathrm{ml}$ ( sesuai pabrik) ditambahkan serbuk $\mathrm{NaF}_{2} 2,27 \%$ (0,068 gr). Setelah setting dan mengeras kuvet dibuka, subyek penelitian dipoles. Kelompok 3 dibuat resin akrilik kuring panas tanpa ditambah fluor dan kelompok 4 resin akrilik kuring dingin tanpa penambahan fluor. Pengujian kekerasan permukaan dengan menggunakan alat Micro Vickers hardness tester. Setiap subyek penelitian pada masing-masing perlakuan diukur sebanyak $5 \mathrm{x}$, kemudian hasil dirata-rata. Data yang diperoleh dianalisis dengan analisis statistik anava 2 jalur.

\section{HASIL PENELITIAN DAN PEMBAHASAN}

Setelah dilakukan penelitian dengan cara mengukur kekerasan basis resin akrilik kuring panas dan kuring dingin yang ditambah dengan sodium fluorida dan tanpa penambahan sodium fluorida, hasil olahan data disajikan pada table 1 sebagai berikut:

Tabel 1. Rerata dan simpangan baku kekerasan resin akrilik kuring panas dan kuring dingin yang ditambah sodium fluorida dan tanpa penambahan sodium flourida ( $\mathrm{g} /$ $\mathrm{mm}^{2}$.)

\begin{tabular}{ccc}
\hline & A1 & A2 \\
\hline B1 & $16,171 \pm 1,249$ & $13,293 \pm 1,725$ \\
\hline B2 & $16,526 \pm 1,205$ & $14,278 \pm 0,982$ \\
\hline
\end{tabular}

Keterangan :

A1 : Resin akrilik kuring panas

A2 : Resin akrilik kuring dingin

B1 : Dengan penambahan sodium fluorida

B2 : Tanpa penambahan sodium fluoride

Pada table 1 terlihat bahwa rerata kekerasan resin akrilik kuring panas tanpa ditambah dengan sodium fluorida didapatkan rerata terbesar yaitu $16,526 \pm 1,205$ dibanding kelompok yang lain, rerata tersebut menurun pada resin akrilik kuring panas apabila resin akrilik tersebut ditambah dengan sodim flourida $16,171 \pm 1,249$. Demikian juga pada resin akrilik kuring dingin menurun kekerasannya setelah ditambahkan dengan sodium fluorida. Apabila dibandingkan antara resin akrilik kuring panas dan kuring dingin baik yang ditambah atau tanpa penambahan terlihat rerata pada kuring panas mempunyai kekerasan lebih besar dibanding dengan resin akrilik kuring dingin, hal ini disebabkan karena dalam proses polimerisasi terbentuknya polimer resin akrilik dengan adanya tambahan fluor akan mengganggu proses polimerisasi tersebut, sehingga hasilnya sifat kekerasan resin akrilik menurun, selain itu senyawa fluor dapat mengubah sifat permukaan plat, karena fluor dapat mempengaruhi sifat penyerapan air. ${ }^{14} \mathrm{Si}-$ fat penyerapan air mempengaruhi kekerasan suatu bahan, semakin mudah menyerap air maka suatu bahan akan menjadi lebih lunak dan sifat kekerasan berkurang. ${ }^{13}$ Tetapi pengurangan ini tidak diperke- 
nankan kurang dari $10 \mathrm{~g} / \mathrm{mm}^{2} .^{15}$

Untuk mengetahui pengaruh kuring panas dan kuring dingin resin akrilik terhadap penambahan dan tanpa penambahan sodium fluoride dalam kelompok serta antar kelompok penghitungan statistik dilanjutkan dengan anava 2 jalur, setelah dilakukan terlihat pada table 2 sebagai berikut :

Tabel 2. Rangkuman analisis variansi dua jalur kekerasan resin akrilik kuring panas yang ditambah sodium fluorida dan tanpa penambahan sodium fluorida dengan resin akrilik kuring dingin yang ditambahn sodium fluorida dan tanpa penambahan sodium fluorida

\begin{tabular}{|c|c|c|c|c|c|}
\hline $\begin{array}{l}\text { Sumber } \\
\text { variasi }\end{array}$ & JK & $\mathrm{Db}$ & RK & $\mathrm{F}$ & $P$ \\
\hline Antar A & 65,690 & 1 & 65,690 & 37,777 & 0,000 \\
\hline Antar B & 4,489 & 1 & 4,489 & 2,582 & 0,117 \\
\hline Inter $A B$ & 0,992 & 1 & 0,992 & 0,571 & 0,445 \\
\hline Dalam & 62,600 & 36 & 1,739 & & \\
\hline Total & 9214,351 & 39 & & & \\
\hline \multicolumn{6}{|c|}{ Keterangan : } \\
\hline JK & \multicolumn{5}{|c|}{ : jumlah kuadrat } \\
\hline $\mathrm{Db}$ & \multicolumn{5}{|c|}{ : derajat bebas } \\
\hline RK & \multicolumn{5}{|c|}{ : Rata-rata kuadrat } \\
\hline $\mathrm{F}$ & \multicolumn{5}{|c|}{ : nilai $\mathrm{F}$} \\
\hline$P$ & \multicolumn{5}{|c|}{ : propabilitas } \\
\hline A & \multicolumn{5}{|c|}{ : resin akrilik kuring panas dan dingin } \\
\hline B & \multicolumn{5}{|c|}{$\begin{array}{l}\text { : penambahan sodium fluoride dan tanpa } \\
\text { penambahan sodium fluorida }\end{array}$} \\
\hline
\end{tabular}

Pada table 2 menunjukkan bahwa pada terdapat perbedaan yang bermakna kekerasan pada resin akrilik kuring panas dan resin akrilik kuring dingin ( $p<0,05$ ), tidak terdapat perbedaan yang bermakna kekerasan pada penambahan sodium fluorida dan tanpa penambahan sodium fluorada, dan tidak terdapat perbedaan yang bermakna pada interaksi antara resin akrilik kuring panas dan kuring dingin dengan penambahan sodium flourida dan tanpa penambahan sodium flourida $(p>0,05)$. Hal ini jelas terlihat bahwa kuring panas resin akrilik mempunyai berat molekul yang lebih besar dan hasil polimerisasi menghasilkan rantai polimer yang lebih panjang sehingga sifat bahan menjadi lebih besar bila dibandigkan dengan kuring dingin resin akrilik. Namun dengan penambahan dan tanpa penambahan sodium fluorida baik pada kuring panas dan kuring dingin resin akrilik didapatkan hasil tidak ada perbedaan yang bermakna dan hal ini tidak sesuai dengan hipotesis pada penelitian ini, tetapi dengan hasil ini menunjukkan bahwa dengan ditambah dan tidak ditambah sodium fluoride kekerasan resin akrilik baik pada kuring panas dan kuring dingin adalah sama, dapat dikatakan bahwa bahan gigi tiruan tersebut tahan terhadap kekuatan mekanis yaitu tahan terhadap abrasi dan goresan, ${ }^{15}$ maka sesuai dengan tujuan akhir dari penelitian bahwa dengan penambahan sodium fluoride sifat bahan tidak berubah, sehingga penelitian tentang fluoridasi melalui gigi tiruan dapat dilanjutkan, dan diharapkan pemberian fluor dalam kadar rendah dan dalam periode yang lama fluor dapat melepaskan diri dari resin akrilik, sehingga upaya pencegahan karies pada pemakai gigi tiruan dapat tercapai. ${ }^{4}$

\section{KESIMPULAN DAN SARAN}

Kesimpulan penelitian ini adalah penambahan sodium fluorida pada resin akrilik kuring panas dan pada resin akrilik kuring dingin tidak mempengaruhi kekerasan basis gigi tiruan sebagian.

Saran akan lebih lengkap apabila pengaruh penambahan fluor dilanjutkan dengan jenis senyawa fluor lain yang juga sering digunakan untuk fluoridasi, demikian juga penelitian terhadap sifat fisik resin akrilik yang lain.

\section{DAFTAR PUSTAKA}

1. Zitz A, Gedalia I, \& Grajower R : Addition of Fluoride Compound to a Acrylic Resin Plates : Bending strength and Fluoride release, J. Oral Rehabil, 1981,8 (1) : 37 -41 .

2. Tuominen, P., Ranta, K., Paunio, I : Wearing ogf Removable Partial Dentures in relation to Dental Caries, Journal of Oral Rehabilitation, Departement of Public Health University of Helsinki, Finland, 2007, 15 (6) : 515 -520.

3. Mirth D B : the use controlled and and sustained release Agent in dentistry : a rewiew of Application for the Control of dental caries, Pharmacology and therapy in dentistry, 1980, $5: 59-67$.

4. Weatherell J A, Deutsch D, \& Robinson C : Assimilation of fluoride by enamel throughout the life of tooth, Caries res, 1977, $11: 85-115$.

5. Murray J J : Fluoride Tooth Paste and Dental Caries, Bristol, $1976: 60-86$.

6. Mellberg J R, Petrou I D, \& Grote N E : Evaluation of Topical Fluoride Preparation, J.Dent, Rest, 1992 ,69 : $771-778$.

7. Duckworth R M, Morgan S N, \& Gilbert R J : Oral Fluoride Measurements for of The Anti Caries Efficacy of Fluoride Treatment, J.Dent.Rest 71, 1992 :636 -640.

8. Robjohn : HPA Compendium of Chemical Hazard Sodium Fluorid, Health Protection Agency, 2008, pp .5 -6.

9. Takarsyah M P : Mekanisme Bakterisidal Pasta Gigi Fluor Terhadap Streptocoocus Mutans, Ceril V, Yogjakarta, 1995, h. 105 - 109.

10. Gedalia I, Strykovski Y, Zilberman Y, \& Brayer L : Fluoride Treatment of Orthodontic Plates and Denture, J. of California. Dent. Ass.1977, 5 (66) : 636 -640.

11. Amerogen A V, Michels L F E, Roukema P A. \& Verman E C L : Fluoride Availability in Human Saliva After dentifrice Use, J.Dent.Res. ,1992, $71: 814-845$.

12. Wefel J S : Effect Fluoride on Caries Development and Progression Using Intra Oral Models, J.dent, res (Spec. Iss) $1990: 626-633$.

13. Kasuga Y, Akiba N, Minakuchi S, Uchida T, Matsushita N, Hishimoto M, \& Hayakawa I : Development of Soft Denture lining Materials containing Fluorinated Monomers, J.Prosthet. Dent, 2008, 52:183-188.

14. Mc Cabe J F : Anderson Applied Dental Material $6^{\text {th }}$ Ed ,Blackwell Scientific Publications, Melbourne, 1985.

15. American Dental Association : Guide to dental Material and Devices, $7^{\text {th }}$ ed, Chicago, $1974: 54-65$ 